\title{
Unit per Milliliter
}

National Cancer Institute

\section{Source}

National Cancer Institute. Unit per Milliliter. NCI Thesaurus. Code C77607.

An arbitrary unit of substance content expressed in unit(s) per milliliter. 